\title{
Action of lithium carbonate on parotid acini
}

Flávia Fusco Veiga ${ }^{1}$, Aline Cristina Batista Rodrigues Johann ${ }^{2}$, Viviane da Silva Kagy ${ }^{1}$, Luciana Trevisan Bittencourt Muniz ${ }^{1}$, Luciana Azevedo Reis Alanis ${ }^{2}$, Edvaldo Antonio Ribeiro Rosa ${ }^{2}$, Sergio Aparecido Ignacio ${ }^{2}$, Antonio Adilson Soares de Lima ${ }^{3}, \mathrm{Sawsan} \mathrm{Abuhamadah}^{4}$, Yusuf S. Althobaiti ${ }^{5}$, Youssef Sari ${ }^{6}$, Ana Paula Camargo Martins ${ }^{8}$, Marina Viola Azevedo ${ }^{8}$ and Grégio AMT ${ }^{*}$

${ }^{1}$ Post-Graduation Student, School of Dentistry, Pontifical Catholic University of Paraná, Curitiba, Brazil

${ }^{2}$ Full Professor School of Dentistry, Pontifical Catholic University of Paraná, Curitiba, Brazil

${ }^{3}$ Associate Professor, School of Dentistry, Federal University of Paraná, Curitiba, Brazil

${ }^{4}$ Associate Professor, School of Pharmacy, The University of Jordan, Amman, Jordan and Fulbright, Visiting Professor and Researcher of Department of Pharmacology, College of Pharmacy and Pharmaceutical, The University of Toledo, Toledo, OH, United States

${ }^{5} \mathrm{PhD}$ Graduate Student in Experimental Therapeutics University of Toledo, College of Pharmacy and Pharmaceutical Sciences, Department of Pharmacology,

Toledo, OH, United States

${ }^{6}$ Associate Professor Senior, Department of Pharmacology, College of Pharmacy and Pharmaceutical Sciences, The University of Toledo, Toledo, OH, United States ${ }^{7}$ Full Professor, School of Dentistry, Pontifical Catholic University of Paraná, Curitiba, Brazil

${ }^{8}$ Technician support, School of Medicine, Pontifical Catholic University of Paraná, Curitiba, Brazil

\begin{abstract}
Objective: The aim of this study is to quantify the number $(\mathrm{N})$ and to measure the volume $(\mathrm{V})$ of acinar cells of parotid gland. The size and the mass of parotid glands were also assessed in rats subjected to chronic lithium carbonate treatment, mimicking the treatment paradigm of bipolar disorder.

Design: Twenty-five male Wistar rats received intra-peritoneal injections of either saline ( $\mathrm{n}=11)$ or lithium carbonate $(60 \mathrm{mg} / \mathrm{kg}$ body weight) for 51 days. The parotid glands of each animal were removed, weighed, measured and processed, and the histological sections stained with hematoxylinand eosin, from which the $\mathrm{N}$ and $\mathrm{V}$ were quantified. Statistical analysis was performed using Student's $\mathrm{t}$ test.

Results: It was found that with the use of lithium, there was a statistically significant increase in the gland size $(1.00 \pm 0.20 \mathrm{~cm})$ and mass $(150.71 \pm 73.95 \mathrm{mg})$ when compared to the control $(080 \mathrm{~cm} \pm 0.17$ and $108.93 \pm 17.00 \mathrm{mg}$, respectively) $(\mathrm{p}<0.05)$. The number of acinar cells and acinar volume was not statistically different when compared control and lithium.

Conclusion: Lithium carbonate may not modify the cell number and volume, indicating that lithium carbonate does not cause changes in morphometric glandular parenchyma. Moreover, the increase inglandular size and mass might suggest that stroma is swollen and this could result in hyposalivation.
\end{abstract}

\section{Highlights}

- Lithium carbonate is a mood stabilizer which can cause hyposalivation.

- The hyposalivation impairs the quality of life of patients.

- We investigated morphological changes in the parotid subjected tolithium carbonate.

- Lithium does not change the number and acinar cell volume.

- Lithium increases the size and weight of the parotid gland.

\section{Introduction}

The information and technological advances haveprovided better quality of life and longevity. On the other hand, there is a significant increase in the number of individuals affected by disorders that have been little studied. Among these are the affective disorders, which are characterized by mood changes with depression, bipolar disorders and thought disorders [1].

Lithium carbonate has been the first drug approved by the Food and Drug Administration (FDA) for the treatment of bipolar mood disorders [2] and has been used for more than 60 years for the treatment of the acute phases and maintenance of bipolar disorders [3,4]. It acts in both depression and mania, as well as it reduces the risk of suicide and short-term mortality [5]. It has been shown that lithium has mood stabilizing activity and neuro-protective properties which prevent apoptosis of neurons [6].

Although lithium is widely used and is effective for the treatment of mood disorders, it also triggers some clinical disadvantages such as polydipsia, unpleasant taste, tremor, and teratogenicity. Its narrow therapeutic index requires routine monitoring of serum hormone concentrations and renal function [5]. For being a fairly prescribed

Correspondence to: Dr. Ana Maria Trindade Grégio, Department of Pharmacology, School of Dentistry, Pontifical Catholic University of Parana, Imaculada Conceição, 1155, Prado Velho, 80-215-901, Curitiba, Paraná, Brazil, Tel: +55 41 3271-2537; Fax: +55 41 3271-1405 E-mail: ana.gregio@pucpr.br

Key words: lithium, salivary gland, hyposalivation, morphometry, parotid gland, glandular parenchyma

Received: May 06, 2016; Accepted: June 20, 2016; Published: June 25, 2016 
medication, it has been increasingly common for dentists to treat patients who use medicines to control psychiatric disorders and that are subjected to its collateral effects [7].

It is well known that a variety of psychotropic drugs have pronounced effects on the function of the salivary glands and which can cause changes in the secretion mechanisms associated with the activation of muscarinic receptors, inducing an anticholinergic effect which causes xerostomia $[4,8,9]$. The reduction or absence of saliva can affect the emotional state of the patient, causing increased morbidity and reduced quality of life [10].

The salivary secretion is controlled by the sympathetic and parasympathetic autonomic nervous system. The sympathetic pathway controls the saliva's quality, as well as the secretion of amylase, proteins and salivary ions [11]. On the other hand, the parasympathetic pathway controls the quantity of saliva by affecting the release of salivary secretions. The parasympathetic effects on salivary secretion occur via muscarinic receptors, by elevating the IP3 concentration $[12,13]$. The steps are orchestrated as follows: the muscarinic receptor in parotid acinar cellsactivates the G protein, resulting in IP2 hydrolysis by phospholipase $\mathrm{C}$, and so produces the intracellular IP3 that stimulates the $\mathrm{Ca}^{2+}$ release from intracellular stores of acini, leading to a higherconcentration of free calcium $[12,14]$. This increase in the $\mathrm{Ca}^{2+}$ intracellularconcentration induces the activation of: a) $\mathrm{Cl}$-pumps, to balance the voltage of the cell and b) $\mathrm{K}^{+}$channel, maintaining the negative membrane potential, preserving the $\mathrm{Cl}$ - efflux into the lumen of the salivary gland. Therefore, the $\mathrm{Na}^{+}$diffuses through the intracellular acinar maintaining electroneutrality. $\mathrm{Na}^{+}$and $\mathrm{Cl}$ - promote a hypertonic intracellular environment, facilitating the entry of water into the acinar lumen, resulting in the production of fluid saliva [13].

The IP3 degradation is also a necessary step in the inositol phosphate cascade to finalize the response to $\mathrm{Ca}^{2+}$. The triphosphate is metabolized by enzymes inositol polyphosphate 5-phosphatase and 1,4,5-triphosphate of inositol 3-kinase, resulting in inositol1,4-bisphosphate and inositol 1,3,4,5- tetrakisfosfato. These are two metabolites that are dephosphorylated by phosphatases, generating the inositol, which along with the cytidine monofosforil fosfatidase, is the inositol lipid precursor necessary to continue signaling. It has been shown that Li interferes with the amount of phosphatidylinositol by inhibiting the activity of inositol mono phosphatase, thereby preventing the recycling of inositol. This inhibitory action of Li results in an accumulation of both inositol monophosphates and cytidine monofosforil fosfatidase, and can culminate in the absence of inositol, implying its important role in the salivary secretion process, both in its production and release $[12,15]$.

The mechanisms through which lithium reduces the salivary flow are not well known so far, this study proposes a histomorphometric evaluation of the parotid acinar cells of rats subjected to lithium carbonate.

\section{Materials and methods}

This study was approved by the Ethics Committee on the Use of Animals (CEUA - Comitêde Ética no Uso de Animais) of the Pontifical Catholic Universityof Paraná (PUCPR - Pontifícia Universidade Católica do Paraná), under the 631/11 registration number.

We used 25 male rats, Wistartype (Rattusnorvegicusalbinus, Rodentia, mammalia), from the Central Animal Facility of the Pontifical Catholic University of Paraná, and weighing approximately $300 \mathrm{~g}$. The rats were kept in plastic cages with water and food ad libitum, respecting the 12 hours light/dark photo period, and acclimated to the laboratory environment for 3 days.

The animals were randomly separated into two groups, the first group (11 rats) is a control group (CG) in which rats were administered intraperitoneal injections of saline (LBS-Laborasa Indústria Farmacêutica LTDA, São Paulo, SP, Brazil)The second group (14 rats) is the lithium group (LG) in which $60 \mathrm{mg} / \mathrm{kg} /$ day of lithium carbonate in saline solution was administered intraperitoneally (BioarteFarmácia de Manipulação LTDA, Piracicaba, SP, Brazil) .The animals received either saline or lithium carbonate treatment for 51 days. . Purity and potency have been certified by the manufacturer. The application was performed through disposable plastic syringes needles U-100 Insulin $1 / 2$ cc 0,05 m (BD ultra-fine TMBD- Becton Driver, NJ).

\section{Biochemical analysis}

After 51 days and 90 minutes of the last administration of lithium carbonate [16], blood samples were collected through intra-cardiac puncture at the time of euthanasia. $6 \mathrm{ml}$ of blood were collected into Vacutainer ${ }^{\circledR}$ tube with gel (BD-Becton Driver, NJ), disposable without anticoagulant.

The biochemical blood analysis was conducted in LANAC Clinical Analysis Laboratory (Curitiba, PR, Brazil), and the serum levels of lithium were measured by the Dimension RXL automatic analyzer (Medcorp-Siemens, Brasília, DF, Brazil) [17].

With this analysis, it was found that the serum level of lithium in LG was $1.30 \pm 0.55 \mathrm{mmol} / \mathrm{L}$.

\section{Excision of parotid gland}

After the blood was collected, the rats were anesthetized and sacrificed by means of an intraperitoneal overdose of sodium thiopental at $120 \mathrm{mg} / \mathrm{kg}$ (Abbott SA, São Paulo, Brazil). The glands were surgically removed and placed in $10 \%$ formaldehyde for $48 \mathrm{~h}$. The specimens were then sectioned longitudinally according to the method used by Gregio et al. [8] The specimens were processed and placed on glass slides containing two histological cuts stained by hematoxylin and eosin (with $4 \mu \mathrm{m}$ in thickness), one from the right gland and one from the left gland.

\section{Histomorphometric analysis}

The specimens were processed and embedded in paraffin following the routine of the PUCPR Experimental Pathology Laboratory, and the 4 micrometers thick histological sections were stained by hematoxylin andeosin.

For the histomorphometricanalysis, 80 images of each blade were captured with 40X and 100X lenses (40 in each), through a Dinolite ${ }^{\circ}$ AM 423X Microcam (AmMo Electronics Corporation, New Taipei city 241, Taiwan) attached to the Olympus ${ }^{\circ}$ BX 50 microscope (Olympus Corporation, Ishikawa, Japan) and a computer (Acer, Aspire One Series, model $\mathrm{ZH} 7$ ). The images were evaluated in analyzer software (Image-Pro ${ }^{\infty}$ Plus, Cybernetics, Maryland). Using the Onofre et al. (1987) [18] methodology, we obtained the cellular volume (V) and number $(\mathrm{N})$, as described below:

Cellular volume quantification $(\mathrm{V})$ : The processed salivary gland volume $\left(V_{p}\right)$ was calculated using the formula: $V_{p}=m / d . r f$, where $m$ is the fresh mass, $d$ is the density and $r$ fare the changes caused by morphological processing. For these calculations we used

$\mathrm{d}=1,089 \mathrm{~g} / \mathrm{cm}^{2}$, a value obtained by the Scherle method (1970), and 
$\mathrm{rf}=0,7$, obtained by the Taga and Sesso method (1978) [19].

In images captured in $40 \mathrm{X}$ was applied a grid with ten vertical lines and ten horizontal lines, determining 100 points $\left(\mathrm{P}_{t}\right)$ symmetrically distributed over the quadrangular area. From these were counted how many points matched the acini $\left(\mathrm{P}_{\mathrm{i}}\right)$. The acinar volume density $\left(\mathrm{V}_{\mathrm{vi}}\right)$ was calculated: $\mathrm{V}_{\mathrm{vi}}=\mathrm{P}_{\mathrm{i}} / \mathrm{P}_{\mathrm{t}}$. The total acinar volume was determined using the formula: $\mathrm{V}_{\mathrm{ti}}=\mathrm{V}_{\mathrm{vi}}{ }^{\mathrm{t}} \mathrm{V}_{\mathrm{p}}[18]$.

In the images captured with the $100 \mathrm{X}$ lens, we obtained the average of the orthogonal diameter of 50 nuclei. It has been estimated then the radius of each nucleus using the formula $r^{2}=\mathrm{d} 1 . \mathrm{d} 2$. The volume of the acinar cells' nuclei was obtained using the formula

$$
V_{n i}=\frac{4}{3} \pi r^{3}[18] \text {. }
$$

Again, in the images captured at $40 \mathrm{X}$, the number of points coinciding with the nuclei $\left(\mathrm{P}_{\mathrm{n}}\right)$ and the cytoplasm $\left(\mathrm{P}_{\text {city }}\right)$ of glandular acinar cells was recorded. The corrected density of the nuclear volume $\left(\mathrm{P}_{\text {ncorr }}\right)$ was determined by the expression $\mathrm{P}_{\text {ncorr }}=\left(\mathrm{P}_{\mathrm{n}} / \mathrm{P}_{\mathrm{n}}+\mathrm{P}_{\text {city }}\right) \mathrm{K}$, where $\mathrm{k}_{\mathrm{o}}$ is the correction factor calculated by the formula

$$
K_{o}=1+\frac{3 t}{2 d}
$$

where $d$ is the diameter of each nucleus and $t$ is the blade section thickness, which was $4 \mu \mathrm{m}$.

The cytoplasmvolume density was corrected through the formula $\mathrm{P}_{\text {cyticorr }}=1-\mathrm{P}_{\text {ncorr }}$.

The reason cytoplasm divided by the acinar cells' nuclei $\left(\mathrm{R}_{\mathrm{c} / \mathrm{n}}\right)$ was defined by: $\mathrm{R}_{\mathrm{c} / \mathrm{n}}=\mathrm{P}_{\text {cyticorr }} / \mathrm{P}_{\text {ncorr }}$.

Finally, the cytoplasmic volume $\left(\mathrm{V}_{\text {cyti }}\right)$ was calculated by the equation $\mathbf{V}_{\text {cyti }}=\mathbf{V}_{\mathrm{ni}} \cdot \mathbf{R}_{\mathrm{c} / \mathbf{n}}$ and the cell volume $(\mathrm{V})$ by the formula $V=$ $V_{n i}+V_{c y t i}[18]$.

Acinar cell number quantification $(\mathrm{N})$ : Total acinar-cell number was determined by the protocols proposed by Onofre, et al. [18]. For determination of the total number of cell nuclei it was used an integrated virtual grid generated by the Image Pro Plus ${ }^{\otimes} 4.5$ for Windows 98 (Media Cybernetics Inc., Georgia, USA) software. In 40 microscopic fields selected at random for each gland, it was counted the number of nuclear images $(n)$ and the number crossing $(c)$ between the margins of the profiles of the nuclear images and the parallel lines of the test system. Knowing the total area examined in $\mathrm{mm}^{2}(A)$, the distance between the lines of the test system $(d)$, the thickness of the secretion $(t)$, and gland processed volume $\left(V_{\mathrm{p}}\right)$, we obtained the total number of acinar-cell nuclei using the equation:

$$
N=2 n \times \frac{V_{p}}{A(c / n \times d+2 t)}
$$

The number of nuclei per unit gland volume $\left(N_{\mathrm{vi}}\right)$ is calculated by the formula: $N_{v i} \frac{N^{\prime} \times t}{(t+2 R-2 K)}$, Where $N_{\mathrm{vi}}$ is the number of nuclei $/ \mathrm{mm}^{3}$, $n^{\prime}$ is the number of nuclear slices and fragments $/ \mathrm{mm}^{3}, t$ is the section thickness, $r$ is the mean radius, and $K$ is the correction factor for nuclear spherical segments that escape counting and correspond to the vertical length of the smallest fragment observed. Here $K$ is calculated by $r^{2}$ $=(r-k)^{2}+r f^{2}$ is the radius of the smallest nuclear spherical fragment observed. By multiplying $N_{\mathrm{vi}}$ by $V_{\mathrm{p}}$ the total number $N$ of acinar cells in the gland was obtained.

\section{Statistics}

The statistical analysis was performed using the program SPSS
20.0 (SPSS Inc, Chicago, IL). The Kolmogorov-Smirnov normality test revealed the variables were normally distributed, choosing then for the Student's t-test. The Levene test found that the variables cell number and gland size presented homogeneous variance, while the others were heterogeneous. The significance level adopted in all tests was $5 \%$. We evaluated the variables' reproducibility power and found that the Dahlberg error ranged from 0.62 to $6.3 \%$, indicating that the single evaluator reproduced reliably measures $[20,21]$. The Student's $t$ test revealed no systematic error in the count $(\mathrm{p}>0.05)$.

\section{Results}

Greater size and mass of the gland were observed in animals treated with lithium. For the other variables, no significant differences were observed (Table 1).

\section{Discussion}

This is the first study that investigated the effects of lithium carbonate on the histomorphometry of rats' parotid glands. It was verified that in the animals treated with lithium, there are: a) a significant increase in the size of parotid gland; b) greater glandular mass; c) equivalence in cellular volume; d) matching the number of cells when compared to the control.

There are several studies $[9,12,22]$ which discussed the possible mechanisms of lithium in reducing salivary secretion causing a hyposalivation due to the lack of nerve stimulation for the synthesis of salivary secretions. Once Lithium does interfere in the connection of the chemical mediator (acetylcholine) with the receiver (M3), are capable of inhibiting nervous impulses as well as the stimuli to release the salivary secretion. However, the blocking may be lithium both salivary secretion and production, in that there is sampled a connection thereof with our findings since the lithium promoted the size and mass increase of the salivary gland $[22,23]$.

For Markitziu [9], besides the functional and morphological alterations of the salivary glands, genetic factors and thyroid function may be involved in hyposalivation related to lithium therapy.

Previous studies with antidepressants and benzodiazepines demonstrated a hyposalivation due to the anticholinergic effects on alpha, beta and GABA receptors. These psychotropic drugs are able to promote acinar hypertrophy on parotid gland (represented by the largest cellular volume) observed in studies of Grégio [8], Mattioli [11], Zaclikevis [24] and Silva [25]. Although lithium is a centrally acting drug and a psychotropic drug, the mechanism of action on the morphology of the parotid acini was different, since there was no change in the acinar volume. This may indicate that lithium has a different pharmacodynamics profile compared to other psychotropic drugs, most likely on some messengers as IP3, by modifying the signal transduction in citoplasmic level.

Table 1. Size and mass of the gland, cellular volume and number of nuclei in the groups lithium and control.

\begin{tabular}{|l|l|l|}
\hline 'Groups/ variables & Lithium (average \pm DP) & Control (average \pm DP) \\
\hline Gland size $(\mathrm{cm})$ & $1.00 \pm 0.20 \mathrm{~A}$ & $0.80 \pm 0.17 \mathrm{~B}$ \\
\hline Gland mass $(\mathrm{mg})$ & $150.71 \pm 73.95 \mathrm{~A}$ & $108.93 \pm 17,00 \mathrm{~B}$ \\
\hline Cellular volume $\left(\mu \mathrm{m}^{3}\right)$ & $1458.88 \pm 287.93 \mathrm{~A}$ & $1711.87 \pm 508.70 \mathrm{~A}$ \\
\hline Cell number $\left(\mathrm{x} 10^{6}\right)$ & $46.75 \pm 25.97 \mathrm{~A}$ & $35.58 \pm 15.04 \mathrm{~A}$ \\
\hline
\end{tabular}

Student's $\mathrm{t}$ test: Different letters in line indicate statistically significant differences, DP: Standard deviation. 


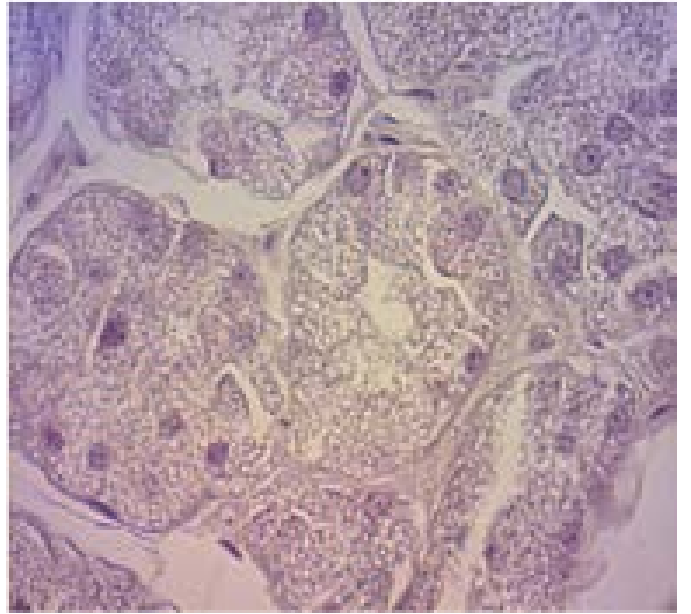

Figure 1. The parotid salivary gland of Wistar rats at 51 days: saline solution. The acini and parenchyma showing a normal acinar architecture, no increase in volume and number of acini. (HE; $40 \mathrm{X}$ magnification).

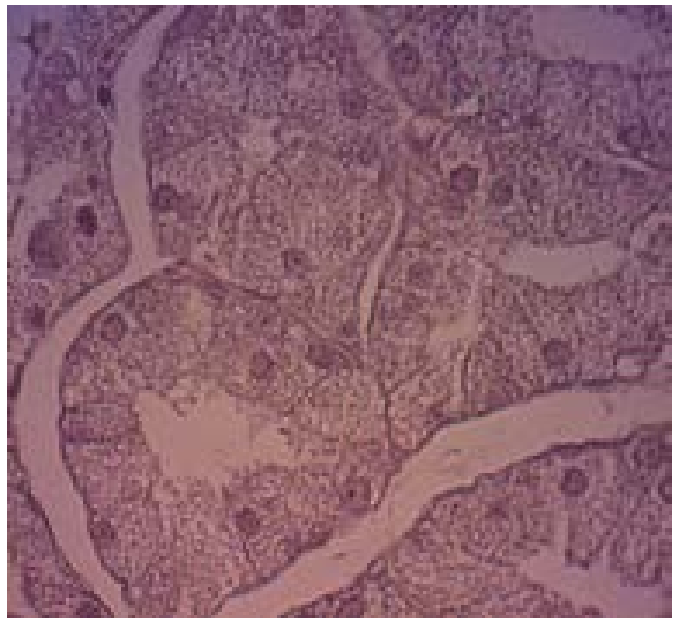

Figure 2. The parotid salivary gland of Wistar rats at 51 days: lithium. The acini and parenchyma with normal acinar architecture, showing that there was no increase in the volume and acinar cell number. (HE; $40 \mathrm{X}$ magnification).

Markitziu et al. (1988) [9], based on sialography and scintigraphy, suggested that the reduction in the salivary flow rate caused by lithium could be resulting from morphological and functional damages occurring in the salivary glands' acini. Our results demonstrate that there are no acinar morphological changes, because there were no significant changes in the cellular number or volume. As a result, the parotid damage that is imposed by lithium is a functional rather than structural.

According to our findings, the functional change, suggested by the size and mass changes, that would influence on release of salivary secretion, which is mediated by the IP3 concentration. Could be cofactors in the alteration of the transduction of signals shown in the work Trisarits [12]

The Li interferes with the amount of phosphatidylinositol by inhibiting the activity of inositol monophosphatase, thereby preventing there cycling of inositol. This inhibitory action of Li results in an accumulation of both inositol monophosphates and cytidine monofosforilfosfatidase, and can culminate in the absence of inositol, so important in the salivary secretion process, both for production and for release [12].
The increased glandular size and mass suggests that there was a possible liquid retention (edema) in the glandular stroma, since there was no change in the parenchyma, represented by the equivalence in cell number and volume between groups. The edema caused by the use of lithium carbonate has been verified in several regions, such as: pretibial, hand, abdomen, pelvic girdle, ankle, eyelids [22], lung [23]. This edema may have been caused by a change inthe redistribution of $\mathrm{Na}^{+}$in the intracellular compartments for the extracellular [24]. This extracellularedema may deteriorate glandular function in term of electrolyte balance, distribution of nutrients and oxygen.

\section{Conclusion}

It was concluded that lithium does not modify the cell number and volume, indicating that there are no morphometric changes in the glandular parenchyma. In addition, the greater size and mass of the parotid gland might suggest that the glandular stroma is swollen and this could result in hyposalivation.

\section{Conflict of interest}

The authors have no conflict of interests.

\section{Ethical approval}

This Study was approved by the Ethics Committee of the Pontifical Catholic University of Paraná (protocol no. 631).

\section{References}

1. Bordin AI, Duarte CS, Peres CA, Nascimento R, Curto BM, et al. (2009) Severe physical punishment: risk of mental health problems for poor urban children in Brazil. Bull World Health Organ 87: 336-344. [Crossref]

2. Rosa AR, Kapczinski F, Oliva R, Stein A, Barros HMT (2006) Monitoring the compliance to lithium treatment. Revista de Psiquiatria Clínica 33: 249-261.

3. Hübers A, Voytovych H, Heidegger T, Dahlhauss FM, Ziemann U (2014) Acute effects of lithium on excitability of human motor cortex. Clin Neurophysiol 3: 1-7. [Crossref]

4. Serdarevic N, Kozjek F, Malesic I (2006) Saliva and serum lithium monitoring in hospitalized patients and possibility to replace serum to saliva. Bosn J Basic Med 6: 32-35. [Crossref]

5. McKnight RF, Adida M, Budge K, Stockton S, Goodwin GM, Geddes JR (2012) Lithium toxicity profile: a systematic review and meta-analysis. Lancet 379: 721-728. [Crossref]

6. YoungW (2009) Review of Lithium Effects on Brain and Blood, Cognizant Communication Corporation. Cell Transplant 18: 951-975. [Crossref]

7. Brown S, Greenwood M, Meechan JG (2010) General medicine and surgery for dental practioners .Part 5. Immunological disease and dental practice. Br Dent J 209: 11-16. [Crossref]

8. Gregio AMT, Durscki JRC, Lima AAS, Machado MAN, Ignacio SA, et al. (2006) Association of amitryptiline and diazepanon the histomorphometry of rat parotid glands. Pharmacol online 2:96-108.

9. Markitziu A, Shani J, Avni (1988) Salivary gland function in patients on chronic lithium treatment. J Oral Surg Oral Med Oral Pathol 66: 551-557. [Crossref]

10. Almeida PDV, Johann ACB, Alanis LRA, Lima AAS, Grégio AMT (2012) Antidepressants: Side Effects in the Mouth. Oral Health Care Pediatric Res Epidemiol Clin Pract: 113-128.

11. Mattioli TM, Silva SD, Grégio AMT, Machado MA, Lima AAS, et al. (2011) The effect of antidepressants and pilocarpine on rat parotid glands: an immunehistochemical study. Clinics 66: 1605-1610. [Crossref]

12. Tritsaris K, Gromada J, Jorgense TD, Nauntofte B, Steen Dissing S (2001) Reduction in the rate of inositol 1,4,5-triphosphate synthesis in rat parotid acini by lithium. Arch Oral Biol 46: 365-373. [Crossref]

13. Nelson DL, Cox MM (2014) Lipids in Lehninger Albert L. Principles of biochemistry. (6 edn.) Porto Alegre: Artmed: 370-371,447,450

14. Nauntofte B (1992) Regulation of electrolyte and fluid secretion in salivary acinar cells. Am J Physiol 263: 823-837. [Crossref] 
15. Levine S, Saltzman A (2006) Lithium increases body weight of rats: Relation to thymolysis. Prog Neuro pycho pharmachol Biol Psychiatry 30: 155-158. [Crossref]

16. Baran DT, Schwartz MP, Bergfeld MA, Teitelbaum SL, Slatopolsky E, et al. (1978) Lithium inhibition of bone mineralization and osteoid formation. J Clin Invest 61: 16911696. [Crossref]

17. Scherle W (1970) A Simple method for volumetry of organs in quantitative stereology. Mikroskopie 26: 57-60. [Crossref]

18. Onofre AM, Souza LB, Campos JA, Taga R (1987) Stereological study of acinar growth in the rat parotid gland induced by isoproterenol. Arch Oral Biol 42: 333-338. [Crossref]

19. Taga R, Sesso A (1978) Avaliação do número de células de órgãos pela dosagem bioquímica de DNA em homogeneizados por contagem direta através de métodos morfométricos. Ciênciae Cultura 30: 1232-1236.
20. Midtgard J, Bjork G, Linder-Aronson S (1974) Reproducibility of cephalometric landmarks and errors of measurements of cephalometric cranial distances. Angle Orthod 44: 56-61. [Crossref]

21. Houston WJ (1983) The analysis of errors in orthodontic measurements. Am J Orthod 83: $382-390.15$

22. Stancer HC, Kivi R (1971) Lithium carbonate and edema. Lancet 2: 985.

23. Petersen CE, Amaral S, Frosh E (2008) Lithium-induced nephritic syndrome in a puberal boy. J Child Adolesc Psycho pharmacol 18: 210-213.

24. Zaclikevis MV, Dágulham AC, Bertassoni LE, Machado MA, Lima AA, et al. (2009) Effects of benzodiazepine and pilocarpine on rat parotid glands: histomorphometric and sialometric study. Med Chem 5: 74-78. [Crossref]

25. Silva S, Azevedo AL, Lima AA, Ignácio AS, Machado MA, et al. (2009) Effects of Fluoxetine and Venlafaxine and Pilocarpine on Rat Parotid Glands. Med Chem 5: 483490. [Crossref]

Copyright: (C2016 Grégio AMT. This is an open-access article distributed under the terms of the Creative Commons Attribution License, which permits unrestricted use, distribution, and reproduction in any medium, provided the original author and source are credited. 